\title{
Knowledge Management Systems: Finding a Way with Technology
}

\section{Abstract}

Purpose

To consider the role of technology in knowledge management in organizations, both actual and desired.

\section{Design/methodology/approach}

Facilitated, computer supported group workshops were conducted with 78 people from ten different organizations. The objective of each workshop was to review the current state of knowledge management in that organization and develop an action plan for the future.

\section{Findings}

Only three organizations had adopted a strongly technology-based "solution" to knowledge management problems, and these followed three substantially different routes. There was a clear emphasis on the use of general information technology tools to support knowledge management activities, rather than the use of tools specific to knowledge management.

\section{Research limitations/implications}

Further research is needed to help organizations make best use of generally available software such as Intranets and e-mail for knowledge management. Many issues, especially human ones, relate to the implementation of any technology.

Participation was restricted to organizations that wished to produce an action plan for knowledge management. The findings may therefore represent only "average" organizations, not the very best practice.

\section{Practical implications}

Each organization must resolve four tensions: 
- Between the quantity and quality of information/knowledge

- Between centralised and decentralised organization

- Between Head Office and organizational knowledge

- Between "push" and "pull” processes

\section{Originality/value}

Although it is the group rather than an individual that determines what counts as knowledge, hardly any previous studies of knowledge management have collected data in a group context.

Key words: knowledge management systems, Journey Making, push and pull approaches, informal systems, centralisation.

\section{Introduction}

One of the fundamental questions in knowledge management is that of the appropriate role of information technology in knowledge management in organizations. There are various possible positions on this. Is an organization's knowledge management system just an information technology one? Is information technology a part, but only a part, of a knowledge management system? Or is information technology really not a key issue in managing an organization's knowledge, compared with others such as people or process issues?

In this paper we try to shed light on these questions, using some of the results of a study into what a variety of organizations in the UK currently do by way of knowledge management, and what they believe they should be doing. We begin by reviewing some of the literature on information technology, knowledge management and knowledge management systems. We then explain the background to our study and briefly describe the methodology we used. We then concentrate on the three organizations in the study that have pursued what we identified as "technology-based" solutions. Discussion of the general issues raised by these three cases (and others) leads to our conclusions and thoughts about the future of knowledge management systems. 


\section{Information Technology for Knowledge Management}

This paper concentrates on technological aspects of knowledge management (KM), although this is not to imply that this is the most important area. Davenport and Prusak (1998) describe KM as involving organizational, human and technical issues, with the advice that the technical should be treated as least important of the three. Dieng et al (1999) add financial, economic and legal issues to this list. Our brief literature review here will similarly centre on technology, and on knowledge management systems, again without wishing to imply that this is therefore the most important aspect of KM.

Many authors have written about the use of various types of software in knowledge management, including Junnakur and Brown (1997), Offsey (1997), Liebowitz (1998), Borghoff and Pareschi (1998), Dieng et al (1999), Alavi and Leidner (1999), Hendriks and Vriens (1999), Earl (2001) and Alavi and Leidner (2001). Since the early days of knowledge management there has been a particular stream of thinking that stresses the use of knowledge-based systems software in knowledge management. Strapko (1990) was discussing this point even before the term knowledge management came into common use, while Liebowitz has been one of its main proponents, arguing that expert systems have a crucial role in institutional memory, because of their ability to capture business rules. Becerra-Fernandez (2000) gives a different kind of example, a people-finder system. It is clear that expert or knowledgebased systems software, and artificial intelligence (AI) software more generally, does have a role to play in supporting knowledge management, but in addition, so does more conventional software. Table 1 shows the most common forms of both AI-based and conventional software that have been suggested by various authors as offering support for knowledge management. It is noticeable that different authors address this discussion in terms varying from the very general (such as knowledge based systems and databases) to the very specific (such as genetic algorithms and workflow). Table 1 shows the terms as authors have used them.

\section{TABLE 1 ABOUT HERE}


Surveys of the use of knowledge management systems include those by Alavi and Leidner (1999) and Zyngier (2001), and a less formal one by Edwards et al (2003b). Our intention is not to go into detail about the various types of supporting software here, discussing their advantages and disadvantages, since our focus in this paper is on which of these systems organizations currently use, and would like to use.

\section{Study Background and Methodology}

\section{The organizations}

We conducted ten workshops, one in each of ten different organizations. Two of the organizations agreed to participate as a result of direct contact made by the researchers. Eight organizations agreed to participate following a mailing to MBA alumni of the university. These contacts became the sponsors of the research and arranged for the participants from their organizations. We sought organizations with a genuine interest in, and concern for knowledge management, and we also wished to ensure that a variety of different sizes and types of organization was included.

Between 5 and 10 participants - all from the same organization - attended each workshop. In total there were 78 participants who came from a variety of functional areas. Each workshop included an accountant, a requirement of our funding from the Chartered Institute of Management Accountants. With that exception the participants in each workshop were those selected by each organization. The criteria suggested by the researchers were that the participants should include "a sufficient spread of people with awareness of, and responsibility for, knowledge management" and also "one person responsible for securing the commitment of resources towards achieving whatever outcomes and actions are decided upon". In the event, most participants were middle or senior managers, with a sprinkling of junior managers and operational-level staff. In all but two of the workshops, one participant was at director-level or equivalent. By having a director present the groups seemed more confident in the strategy they were generating as they were getting immediate informal feedback on how the board might react, and so were able to appreciate whether or not they would realistically be allowed to implement any proposed actions. 
Of the ten organizations, six were for-profit, three were not-for-profit or non-profitdistributing and one was public sector. One of the not-for-profit organizations also received significant government funding. Three of the six for-profit organizations were listed PLCs, two of which were divisions of FTSE 100 companies. Two organizations were privately owned and one was a subsidiary of an overseas PLC.

In terms of 'business' sector, one was in retailing, two in manufacturing, one in design/distribution, three in services, one in consumer protection, one in social housing and the public sector organization was a police force.

The participating organizations are summarized in Table 2. The identity of the organizations has been disguised for reasons of confidentiality.

\section{TABLE 2 ABOUT HERE}

As part of our analysis (Edwards et al., 2003a), we classified the organizations' preferred knowledge management "solutions" into three types: technology, people and process based. Five organizations' approaches were classified as people based (HighTechManuf, Consult, B2BService, R\&D, and Housing). Two were process based (ManufIndProd and ConsumProt). We add further detail here on the three organizations preferring an approach to knowledge management that placed a particular emphasis on technology:

1. Restaurants was the restaurants division of a listed PLC operating under about a dozen major brand names throughout the UK. Restaurant turnover was $£ 1$ billion in the last financial year. Most participants were from the Planning and Insight Department. Because of the selection of participants, the workshop emphasised 'Head Office' knowledge rather than the knowledge in the operating units.

2. Police was an English police force with 2,400 police officers, 1,300 support staff and a budget of $£ 144$ million. Prior to the workshop, Police had increased the police levy (the portion of the council tax that pays for police services) by 
$33 \%$ and wanted to develop a communications strategy, "a shared commitment to a shared plan".

3. DesignInst was the design and installation division of a high technology equipment supplier, a subsidiary of an overseas listed company. They were implementing a new enterprise accounting system and wanted to "make sense of the information we have".

\section{The workshop approach}

The methodology used to run the workshops is one that has evolved during more than 15 years of research, initially called SODA (Strategic Options Development and Analysis) (Eden and Ackermann, 1989) and more recently being renamed Journey Making to take account of advances in the method (Eden and Ackermann, 1998). Journey Making, a mnemonic for JOint Understanding, Reflection, NEgotiation of strategY, supports groups in surfacing, exploring, synthesising and critically reflecting for personal and collective learning (Shaw et al., 2003).

During a Journey Making workshop computer technology is used extensively to help the participants to surface, explore and synthesise their views. Each participant has access to a laptop computer which is networked. Instead of shouting out views to the facilitator, or writing them onto 'post-it' ${ }^{\odot}$ notes, participants type their views into the computer which is running a brainstorming-type software, Group Explorer. The views are normally 4-10 words in length to make them descriptive, rather than cryptic, to the other participants.

Once participants have finished typing their views into the computers, all the views are shown on a large projection screen using Decision Explorer software. They will have been clustered by content by the facilitator, to assist the group members cognitively to manage the mass of information on the screen (up to 100 different views) (Grise and Gallupe, 1999). Then participants have the opportunity to read other participants' views, expand on them, or critique them (Shaw, 2003). 
Following this activity group discussion ensues on the views, clusters and causal relationships. Normally a large number of views are considered and a tremendous amount of complexity arises. The different perspectives of (up to) 15 people are each considered systematically using a transparent, structured and logical process. This ensures that, (1) the group will make real progress rather than going round in circles; (2) there is equalisation of air-time between participants, reducing the dominance of any individuals; (3) each option can be fully considered before being dismissed or integrated into the action plan.

Computer brainstorming has the advantage that people, (1) can share ideas/views simultaneously, rather than all fighting for "air-time" (Pinsonneault et al., 1999); (2) have anonymity when they share their views, to encourage controversial views to be shared (Cooper et al., 1998); (3) can accurately record their views, rather than a facilitator misunderstand (Eden and Ackermann, 1998); (4) the group can edit and move views, en masse, rapidly.

The output from this process takes the form of a group causal map, or strategic map, an example of which is shown in Figure 1. (This example, from B2BService, has been chosen to show that there was more to the workshop discussions than IT.) This map can be analysed to identify a range of actions which might be implemented to improve the situation. Group consideration and negotiation supports the identification of the right actions to implement. Through this entire process the participants are building a map, negotiating agreement, and giving commitment to the group to support action being taking to address the situation (Eden and Ackermann, 1998).

\section{FIGURE 1 ABOUT HERE}

\section{A consistent four-stage process}

In this research we adopted a consistent approach to all the workshops. This involved having the same facilitator, and either one or two observers. We also used identical technology and software and a standard four-stage agenda, which consisted of:

Stage 1: What knowledge informs your business?

Stage 2: What processes are currently used to harness this knowledge?

Stage 3: What processes should be used to harness this knowledge? 
Stage 4: How do we (or should we) evaluate how good we are at harnessing this knowledge? \{"We" here referring to the participants' organization.\}

Although this agenda was consistent, it was used flexibly rather than restrictively. We recognised that there was no one best solution to knowledge management, and so allowed each organization to determine the specific content of the workshops within the broad field of knowledge management and the research questions, to suit their own interest.

After the first session (which was necessary to get the group thinking together about knowledge management) the participants decided whether our agenda was appropriate for them and "whether \{they\} would regret not having discussed something else". Sometimes the group followed our agenda throughout, but more often they added sessions and refocused others to be more relevant to the expertise in the group and the urgency of particular issues. For example, one group added a session which asked "How can we get reluctant people to pull information off the Intranet?" The debate which surrounded the validation/amendment of our agenda provided insight into the pressing knowledge management issues which faced the organizations.

\section{Extent of Technology Use in KM}

The workshop discussion covered many aspects of knowledge management in the participating organizations. In this paper we concentrate on knowledge management systems and the role of information technology, but discussion of other issues may be found in Edwards et al (2003a). Of the ten organizations in the study, information technology was a significant element of the discussion in all but one of them. The one exception was ManufIndProd, where although two types of information technology (e-mail and knowledge-based systems) were mentioned during the identification of processes that were relevant to current $\mathrm{KM}$, neither was pursued in the subsequent detailed discussions. We now summarise the discussion relating to information technology firstly in the three organizations in which it was the major focus of discussion, and then in the six organizations where it was a significant but minor element. This includes the various types of IT that participants mentioned as being relevant to supporting $\mathrm{KM}$, and a little indication of the context of the discussion. Direct quotations from workshop participants are shown in Italics. 


\section{Restaurants}

A feature of the workshop held for Restaurants was its focus on "Head Office" knowledge (such as sales, marketing and financial aspects) rather than on "operational" knowledge (such as how to cook and serve meals in the restaurants, which dishes were most popular, and so on).

Restaurants claimed to make extensive use of technology in supporting knowledge management, including Internet searching, an Intranet, MIS, accounting and payroll systems (the latter "for details about staff"), shared databases, an "electronic library" and an externally held data warehouse. They also talked about "cubes" of information, by which they meant OLAP-style analyses, although these were not yet available because of the unreliability and inconsistency of the data.

Their desire for the future was thus for a single source of knowledge that required standard site technology... "the long term fix is dependent on a technological solution”. Interestingly, plans were already in hand for such a technological solution to be implemented, but until the workshop took place the participants did not seem to have appreciated the significance of this system as regards KM. There was definitely an "Aha" moment during the workshop as this became apparent, and the new system became more and more central to the action plan for KM that they were trying to devise.

The best way to describe Restaurants is that they were led to a technological approach to $\mathrm{KM}$ - perhaps due to a focus on understanding the customer. Despite the extensive use of technology in Restaurants, participants had a broad view of KM but realised during the workshop how important technology was to it.

\section{Police}

Police as an organization was new to formal KM, and the managerial initiative that led to their participation took a broad view of what KM meant. However, most of the suggestions and discussion in the workshop were strongly technology based. Police forces in general make extensive use of information technology and indeed other 
types of technology (everything from helicopters to DNA profiling), and this force is no exception.

Current uses of IT for KM included email, the Intranet, and the Police National Computer, although more than any other organization the descriptions often concentrated on the hardware (e.g. notebooks or personal organizers) rather than on what was done with it. Police also make extensive use of video, although discussion of this technology is beyond the scope of this paper.

A great deal of the discussion in the workshop focussed on how much and how well the official IT systems were used, as illustrated by the following quotes: "How many people are logged on \{is not a good measure\} ... of how many people used it. A whole room will use data if one person is logged on"

"A PC \{police constable\} has to access information at the beginning of their shift before going on patrol to be able to do their job"

"We need to make some things only available via the Intranet, for example \{forms for\} expense payments, annual leave, overtime"

An issue not raised in any other workshop was that of the use of unofficial IT systems. "Privately owned organizers and laptops that people shouldn't have are a barrier to communication"

The overall focus of the Police workshop was on communications. For the future, the Intranet was ranked as the most effective tool for corporate communications and second (after intelligence led policing) for operational communications: "if you only put information in one place, that is where people will go to use it". A corporate web site was also identified as a good way to communicate with external stakeholders.

The best description for this case is that police were opportunist with information technology, or indeed that they cannot keep away from technology - to improve processes and provision to "customers"/stakeholders. 


\section{Designlnst}

DesignInst's attitude to KM was definitely technology-driven, although there is scope for a little debate as to whether they were driven to technology, because of the support needed for their business processes, or driven by technology, with their interest in KM arising from the introduction of a new information system. It was this system, and the uses that could be made of it, that formed the focus for the workshop.

Discussion in this workshop concentrated almost entirely on the future, rather than the present. They identified their new "enterprise accounting system" as a key resource for all aspects of the business, including $\mathrm{KM}$, and also the need to make fragmented knowledge more coherent.

Examples of this included a discussion of online access to stock availability. One participant said "The management system will not do anything for us in relation to 'how do we find new customers",. The same person also said that "not enough time spent on outward looking areas, we are too inward looking”. Another commented that "The nature of what is produced is that the system doesn't provide product development information". A frequent theme was the need to define a list of MIS requirements and reduce duplication of information held. They called this a "flight deck" for the business.

Interestingly, what was never explicitly discussed was whether the new system addresses the clusters that participants identified during the workshop as the key elements of knowledge their organization needed.

There was a real conflict in the workshop between the 'systems' side of the business and the 'product' side, hence the difference between the two themes of reducing duplication and satisfying customers.

\section{HighTechManuf}

Current uses of information technology for KM were identified as including the Internet (for searching), an Intranet, email, bulletin boards and shared files. They also identified that the organization had "islands" (meaning they were unconnected) of 
databases. In considering the processes that HighTechManuf should use for KM, the participants discussed a cluster of ideas related to IT, but the focus was on internal communications (the label given to the cluster) rather than the technology itself. By internal communications they meant what needed to be communicated, and to whom. This was typical of their overall "people" focus. Much of the discussion centred on sharing and storing operational manufacturing knowledge, for which solutions such as a printed sheet of instructions (laminated to resist grease etc.) were preferred to an information technology solution.

\section{Consult}

Current uses of IT for KM in Consult included email, Internet, Intranet and shared databases. In discussion they characterised databases as a "compendium of knowledge". A specific concern was the over-use of email, which resulted in a suggestion for 'message boards' rather than 1-to-1 emails. They also wished to see more and better integrated databases. Again, their overall focus was on people, especially in relation to business aspects, rather than technology.

\section{B2BService}

Current IT relevant to KM was identified as including email, sundry databases, and accounting software. The focus of their discussions on KM was very much more concerned about market than processes "if we are driven by internal process issues we will fail in the marketplace". Thus they considered "how to achieve KM" - "KM through ..." under a variety of headings, including a large cluster of ideas labelled "KM through IT", as shown in the map in Figure 1. Items here included an Intranet (and access to it from offsite), an Extranet, a data warehouse, better MIS, video conferencing, better use of the web and protocols for the use of email. Although technology was clearly an important element, people were seen as an even more important aspect, as witness the clusters on human resources and (social) networking. 
This organization was a very advanced information technology user. Systems identified as relevant to KM included databases (internal and external), email, bulletin boards, the Internet, and an Intranet. However, they felt that the introduction of this technology had not always been effective. "Informal mechanisms have been replaced by formal email and the information doesn't get shared as well". They also had a history of confidentiality (because of the nature of their work) which meant that many databases were not accessible, one participant called this "anal"! Looking to the future, they stressed the need for scanning of documents to help form a centralised document repository, enabling Intranet access and search, and with abstracting features. However, they felt that technology was not the main issue in KM in their organization. Rather, it was crucial to concentrate on the people aspects, especially the fact that the nature of the business had undergone a significant change.

\section{Housing}

Current uses of information technology for KM discussed in this workshop included email, an Intranet, and shared files. Housing was also the only organization to mention the current use of its own web site for communicating knowledge to external partners. For the future, participants talked about an "electronic library" and encyclopaedia, plus an Extranet, and a portal for news reports etc. They identified a critical need for "summarising, abstracting, disseminating" rather than just placing files somewhere where people might (or might not) choose to access them. However, this was a relatively minor part of the discussion compared to their interest in partnerships and (social/organizational) networking, and in the issues raised by staff being split between their two main offices.

\section{ManufIndProd}

ManufIndProd's discussion concentrated on processes because of the recent management buyout and a possible future change of location of their only site. 


\section{ConsumProt}

ConsumProt also had a process focus to their discussions on KM. In discussing current processes, they identified email and a cluster of more than a dozen items relating to different databases. Interestingly, participants chose to include MS Word and MS Project files in this cluster. Despite this extensive discussion about retaining knowledge, or perhaps information, in databases, participants felt that it probably was not important to develop technology further. This was mainly because of the difficulty of achieving any payback on such an investment over ConsumProt's limited future life. (Its functions as a voluntary regulatory body are due to be taken over by a statutory body in approximately two years.) In the circumstances, they thought it more important to transfer knowledge to people's heads to enable them to get replacement jobs, and also to be able to transfer knowledge to the replacement organization. The latter need in particular accounted for much of the process focus.

Table 3 summarises the various IT-based knowledge management systems mentioned by participants in the ten workshops.

\section{TABLE 3 ABOUT HERE}

\section{Discussion}

Although based only on a small and relatively informal survey, the paper by Edwards et al (2003b) gives a flavour of the expectations of academics and practitioners about different types of knowledge management system. Those most often cited were Intranets, groupware, search and retrieval tools, and data mining software. The type of information technology support most favoured for specific uses in their survey was groupware, but interestingly no use of groupware for $\mathrm{KM}$ was mentioned in this sample of cases at all. Perhaps this may have been because our sample did not include any management consultancies; they were amongst the pioneers of groupware, and are probably the most advanced users of it. In fact, the only interest expressed in groupware was that participants in at least two of the workshops enquired about buying their own copies of the software that was used to run the workshops. 
In the cases we studied, there was a clear emphasis on the use of general information technology tools (such as e-mail, shared databases and Intranets) to support KM activities, rather than the use of tools specific to KM. This is consistent with the findings of Zhou and Fink (2003 (to appear)) for Australian organizations. The best example of a specific KM tool that we found was that Restaurants strongly advocated the use of a data analysis system based on OLAP or business intelligence principles (their reference to "cubes of data"). Restaurants already used an external data warehouse. B2BService also wanted to see a data warehouse, while R\&D and Housing were interested in repositories, although the discussion on this topic in the Housing workshop seemed to have a "pie in the sky" element to it.

With the more general tools, the issue seems to be how to use them effectively in supporting KM. None of the organizations with Intranets seemed to be confident that they were using them well, or even that they knew how to use them well. Email was used in all of the ten organizations (although one did not see a significant connection with $\mathrm{KM}$ ), but in almost every case there was dissatisfaction with its use, especially the tendency to copy everyone in on everything. All of the organizations saw shared databases of some kind as important for $\mathrm{KM}$, but there was often uncertainty as to how best to achieve this.

It is generally accepted that there is no "one size fits all" solution to the use of technology to support KM in organizations. Three of our ten organizations emphasized technology; at the other end of the scale, two scarcely mentioned it. What each organization has to do in terms of supporting its $\mathrm{KM}$ activities is to strike an appropriate balance between various tensions apparent in the organization. This balance will differ, not only between different organizations, but also perhaps for the same organization at different times.

We have identified four related tensions influencing decisions about IT and KM. The first is the tension between the quantity and the quality of the information and knowledge being managed (not helped by the confusion between information and knowledge displayed by many participants). Examples of this were Restaurants' inclusion of the payroll system as a source of support for KM, and a strong emphasis on shared databases in several workshops without much specific discussion of their 
content. A relevant question is: "Has technology simply increased the volume of unfocused data without helping to convert it into usable knowledge?" This reinforces findings elsewhere in the literature: as Alavi and Leidner (2001) put it "Hoards of information are of little value".

Related to this is the second tension, between centralised and decentralised organizations. Restaurants, as we have seen, wanted a centralised "solution": a single source of knowledge based on standard site technology. However, this may have been influenced by the fact that all of the workshop participants were from Head Office. Police were very aware of this tension, especially the use of what one might call "independent" KM technology (ranging from the unofficial to the dubiously legal). DesignInst expressed this tension as being between an inward and an outward focus. A question arising here is: "Does the decentralised organization conflict with centralised knowledge 'systems' - does the KM strategy imply a more centralised organization?" This raises significant issues about the roles of the formal and informal organization in knowledge management. The importance of the informal organization, especially social networks, has long been recognised in management literature generally; see for example Krackhardt and Hanson (1993). These ideas have been taken note of in the knowledge management literature, although as Holtham and Courtney (1998) point out, informal mechanisms may preclude wide dissemination of knowledge. However, we believe that the relevance of informal information systems to knowledge management, such as those in Police, has not been previously recognised.

A third related tension is between "Head Office" and operational knowledge. Restaurants scarcely considered operational knowledge at all in their workshop. For Police this tension is a well-known problem, but unfortunately without a well-known solution. Anecdotal evidence in Police is that operational knowledge is shared reasonably effectively, but greater efforts to systematize this may have the opposite of the desired effect. This had already happened in a pilot project in another organization, R\&D. A question arising here is "Who decides which knowledge needs to be managed?" This does not appear to have been addressed so far, at least in the literature relating to knowledge management systems. 
The fourth tension is between "pushing" information and knowledge out to people and leaving them to "pull" it when needed. There was general agreement that universal "push" systems did not work. This is consistent with the literature, e.g. (Damodaran and Olphert, 2000). Holtshouse (1998) explains the need to balance push and pull approaches. However, Police in particular recognised that some people were much more likely to choose to pull knowledge for themselves than others were. A question here is thus: "How does one involve what one Police participant called 'recalcitrant non-communicators'?" The need to involve those who might least wish to be involved has been raised in other information systems contexts, for example expert systems; see Edwards et al (2000).

Finally, we see the general problems of alignment - making sure that the solution fits the organization's business processes. This is shown by the very different technologybased solutions favoured by DesignInst, Restaurants and Police.

\section{Conclusions}

Different solutions are appropriate and organizations need to find the solution which is right for their context. There is a range of approaches that can be taken in considering technology to assist KM - even just three technology-focussed cases, as reported here, give three very different approaches.

Within this we have identified four tensions that each organization must resolve:

- Between the quantity and quality of information/knowledge

- Between centralised and decentralised organisation

- Between Head Office and organizational knowledge

- Between "push" and "pull” processes

Finding the way to make best use of generally available software such as Intranets and e-mail for KM is perhaps the biggest single challenge.

Whatever technological route is adopted, there will also be many issues, especially human ones, relating to the implementation of that solution. There is insufficient room to address these here. 


\section{Limitations}

The most apparent limitation of the study is that participation was restricted to organizations that expressed an interest in knowledge management, and presumably wished to receive some assistance from the researchers. This would therefore exclude both those who had no interest in KM, and, more importantly, those who felt that they did not need any assistance with KM. Our findings may therefore represent only "average" organizations, not the very best practice.

Although our study was limited to UK organizations, we believe that the findings will still be representative of organizations in other industrialised countries, because of the variety of organizations covered. This will be true unless there are countries significantly ahead of, or behind the UK in KM adoption.

\section{Acknowledgements}

This research was funded by CIMA, the Chartered Institute of Management Accountants in the UK. The authors are also grateful for the comments of the anonymous referees.

\section{References}

Alavi, M. and Leidner, D. E. (1999), "Knowledge management systems: issues, challenges and benefits", Communications of the AIS, Vol 1 Article 7.

Alavi, M. and Leidner, D. E. (2001), "Review: Knowledge Management and Knowledge Management Systems: Conceptual Foundations and Research Issues", MIS Quarterly, Vol 25 No 1, pp. 107-136.

Becerra-Fernandez, I. (2000), "The role of artificial intelligence technologies in the implementation of people-finder knowledge management systems", Knowledge Based Systems, Vol 13 No 5, pp. 315-320.

Borghoff, U. and Pareschi, R. (1998), Information technology for knowledge management, Springer, New York.

Cooper, W. H., Gallupe, R. B., Pollard, S. and Cadsby, J. (1998), "Some liberating effects of anonymous electronic brainstorming", Small Group Research, Vol 29 No 2, pp. 147-178.

Damodaran, L. and Olphert, W. (2000), "Barriers and facilitators to the use of knowledge management systems", Behaviour and Information Technology, Vol 19 No 6, pp. 405-413. 
Davenport, T. H. and Prusak, L. (1998), Working knowledge : how organizations manage what they know, Harvard Business School Press, Boston, Mass.

Dieng, R., Corby, O., Giboin, A. and Ribiere, M. (1999), "Methods and tools for corporate knowledge management", International Journal of Human-Computer Studies, Vol 51 pp. 567-598.

Earl, M. (2001), "Knowledge management strategies: Toward a taxonomy", Journal of Management Information Systems, Vol 18 No 1, pp. 215-233.

Eden, C. and Ackermann, F. (1989), "Strategic Options Development and Analysis (SODA) - using a computer to help with the management of strategic vision", in Doukidis, G. I., Land, F. and Miller, G. (Eds) Knowledge-based Management Support Systems Ellis Horwood, Chichester, pp. 198-207.

Eden, C. and Ackermann, F. (1998), Making Strategy: The Journey of Strategic Management, Sage, London.

Edwards, J. S., Collier, P. M. and Shaw, D. (2003a) CIMA, London.

Edwards, J. S., Duan, Y. and Robins, P. C. (2000), "An analysis of expert systems for business decision making at different levels and in different roles", European Journal of Information Systems, Vol 9 No 1, pp. 36-46.

Edwards, J. S., Handzic, M., Carlsson, S. and Nissen, M. (2003b), "Knowledge Management Research \& Practice: Visions and Directions", Knowledge Management Research \& Practice, Vol 1 No 1, pp. 49-60.

Grise, M. L. and Gallupe, R. B. (1999), "Information overload in face-to-face electronic meetings: An integrative complexity approach", Journal of Management Information Systems, Vol 16 pp. 157-185.

Hendriks, P. H. J. and Vriens, D. J. (1999), "Knowledge-based systems and knowledge management: friends or foes?" Information and Management, Vol 35 No 2, pp. 113-125.

Holtham, C. and Courtney, N. (1998) In Fourth Americas Conference on Information Systems(Eds, Hoadley, E. and Benbasat, I.) Baltimore, MD, pp. 594-597.

Holtshouse, D. K. (1998), "Knowledge Research Issues", California Management Review, Vol 40 No 3, pp. 277-280.

Junnarkar, B. and Brown, C. V. (1997), "Re-assessing the enabling role of information technology in KM", Journal of Knowledge Management, Vol 1 No 2, pp. 142-148.

Krackhardt, D. and Hanson, J. R. (1993), "Informal Networks - The company behind the chart", Harvard Business Review, Vol 71 No 4, pp. 104-111.

Liebowitz, J. (1998), "Expert systems: An integral part of knowledge management", Kybernetes, Vol 27 No 2, pp. 170-175.

Offsey, S. (1997), "Knowledge management: Linking people to knowledge for bottom line results", Journal of Knowledge Management, Vol 1 No 2, pp. 113-122.

Pinsonneault, A., Barki, H., Gallupe, R. B. and Hoppen, N. (1999), "Electronic brainstorming: The illusion of productivity", Information Systems Research, Vol 10 pp. 110-133.

Shaw, D. (2003), "Evaluating electronic workshops through analysing the 'brainstormed' ideas", Journal of the Operational Research Society, Vol 54 No 7, pp. 692-705.

Shaw, D., Ackermann, F. and Eden, C. (2003), "Sharing knowledge in group problem structuring", Journal of the Operational Research Society, Vol 54 No 9, pp. 936-948.

Strapko, W. (1990), "'Knowledge management' - a fit with expert tools", Software Magazine, November 1990, pp. 63-66. 
Zhou, A. Z. and Fink, D. (2003 (to appear)), "Knowledge Management and Intellectual Capital: An empirical examination of current practice in Australia", Knowledge Management Research \& Practice, Vol 1 No 2.

Zyngier, S. (2001), "The role of technology in knowledge management: Trends in the Australian corporate environment", in Burstein, F. and Linger, H. (Eds) Knowledge Management in Context Australian Scholarly Publishing, Melbourne, pp. 78-92. 
Figure and Table Captions

Figure 1: An example of a map produced in one of the workshop sessions

Table 1: Different types of support for knowledge management

Table 2: Participating organizations

Table 3: Use of IT in KM - current systems (shown as X) and suggested future (shown as $\mathrm{O}$ ) 


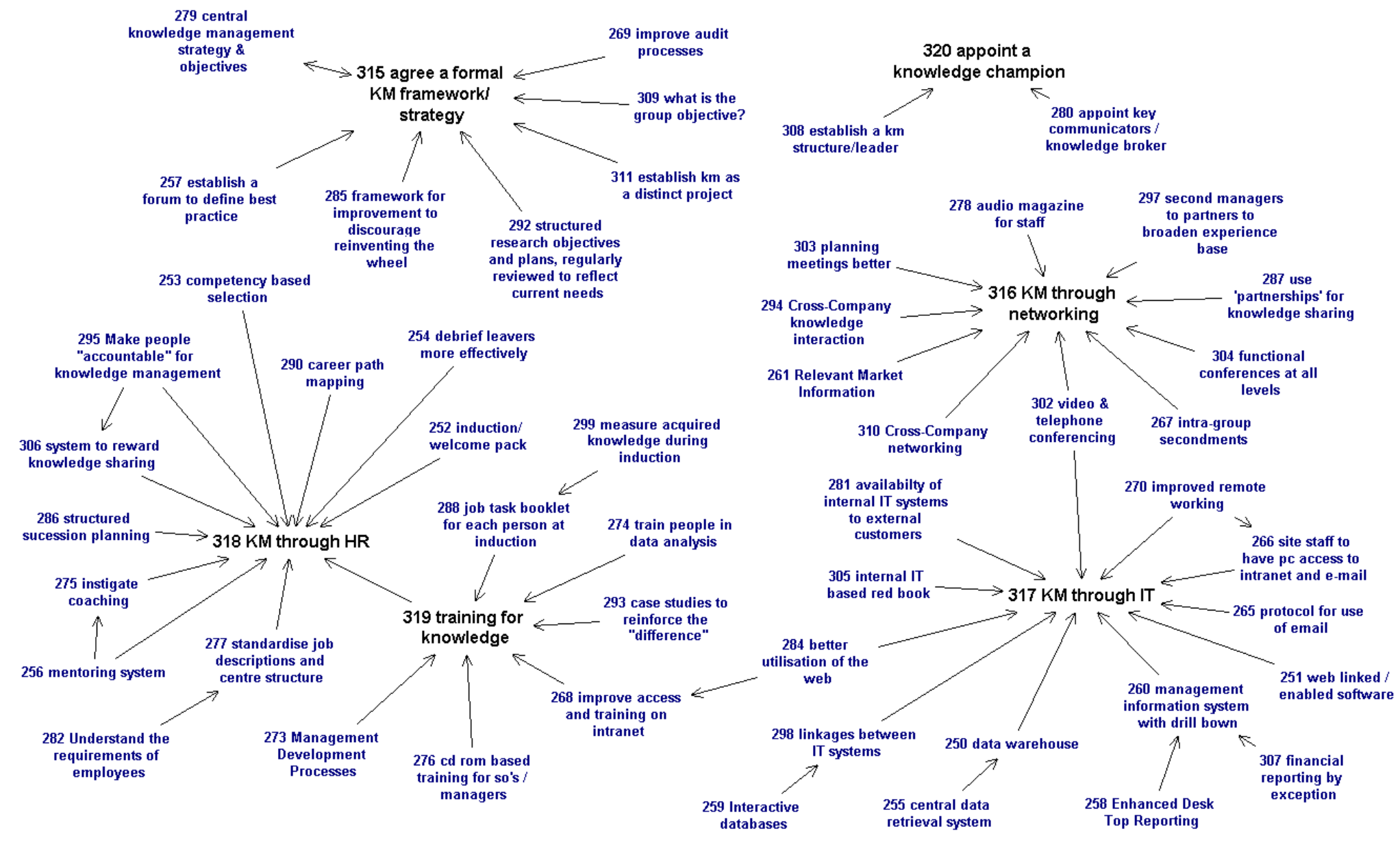




\begin{tabular}{|l|l|}
\hline Al-based & Conventional \\
\hline Case-based reasoning & Bulletin boards \\
\hline Data mining & Computer-supported co-operative work \\
\hline Expert systems & Databases \\
\hline Genetic algorithms & Data warehousing \\
\hline Intelligent agents & Decision support systems \\
\hline $\begin{array}{l}\text { Knowledge based } \\
\text { systems }\end{array}$ & Discussion forums \\
\hline Multi-agent systems & Document management \\
\hline Neural networks & Email \\
\hline "Push" technology & Electronic publishing \\
\hline & Executive Information Systems \\
\hline & Groupware \\
\hline & Information retrieval \\
\hline & Intranets \\
\hline & Multimedia/hypermedia \\
\hline & Natural language processing \\
\hline & People finder/“Yellow Pages" \\
\hline & Search engines \\
\hline & Workflow management \\
\hline
\end{tabular}




\begin{tabular}{|c|c|}
\hline Organization & Brief description of organization \\
\hline Restaurants & $\begin{array}{l}\text { Retail/Service business with about } 12 \text { major brand names, } \\
\text { division of FTSE100 PLC }\end{array}$ \\
\hline Police & Public sector/Police force with 3,700 staff and £140M budget \\
\hline DesignInst & $\begin{array}{l}\text { Design/installation of high technology equipment, subsidiary of } \\
\text { overseas listed company }\end{array}$ \\
\hline HighTechManuf & $\begin{array}{l}\text { Manufacturing high technology, £100M turnover and } 800 \\
\text { employees, privately owned }\end{array}$ \\
\hline Consult & $\begin{array}{l}\text { International technical/engineering consultancy, division of } \\
\text { FTSE100 PLC }\end{array}$ \\
\hline B2BService & $\begin{array}{l}\text { Business-to-business services, } 12,000 \text { employees, Turnover } \\
£ 200 \mathrm{M} \text {, listed PLC }\end{array}$ \\
\hline $\mathrm{R} \& \mathrm{D}$ & $\begin{array}{l}\text { Non-profit distributing membership-owned research and } \\
\text { development, 550 employees }\end{array}$ \\
\hline Housing & $\begin{array}{l}\text { Non-profit registered social landlord, } 500 \text { employees managing } \\
5,500 \text { homes }\end{array}$ \\
\hline ManufIndProd & Manufacturing industrial products, privately owned \\
\hline ConsumProt & $\begin{array}{l}\text { Not-for-profit membership owned non-statutory consumer } \\
\text { protection body }\end{array}$ \\
\hline
\end{tabular}




\begin{tabular}{|c|c|c|c|c|c|c|c|c|c|c|c|c|c|c|}
\hline Organization & 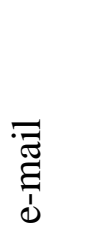 & $\begin{array}{l}\stackrel{\overrightarrow{0}}{0} \\
\stackrel{0}{0} \\
\stackrel{0}{0}\end{array}$ & 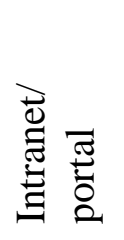 & 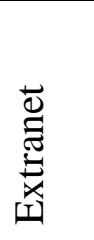 & 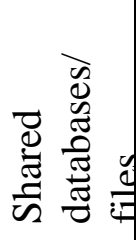 & 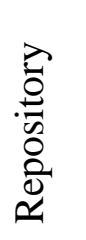 & 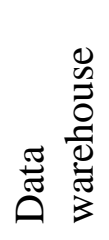 & 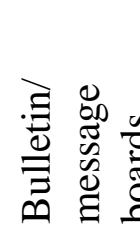 & $\tilde{a}$ & 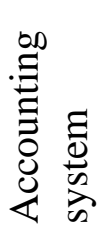 & 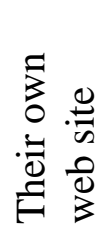 & $\stackrel{\Omega}{\Sigma}$ & $\frac{2}{4}$ & 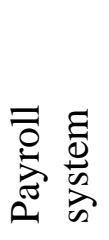 \\
\hline Restaurants & $X$ & $\mathrm{X}$ & $\mathrm{X}$ & & $\mathrm{X}$ & $\mathrm{X}$ & $\mathrm{X}$ & & & $X$ & & $X$ & $\mathrm{O}$ & $X$ \\
\hline Police & $X$ & $\mathrm{X}$ & $\mathrm{X}$ & & $X$ & & & & & & $\mathrm{O}$ & & & \\
\hline Consult & $\mathrm{X}$ & $\mathrm{X}$ & $\mathrm{X}$ & & $\mathrm{X}$ & $\mathrm{O}$ & & $\mathrm{O}$ & & & & & & \\
\hline B2BService & $\mathrm{X}$ & $\mathrm{O}$ & $\mathrm{O}$ & $\mathrm{O}$ & $X$ & & $\mathrm{O}$ & & & $\mathrm{X}$ & & & & \\
\hline $\mathrm{R} \& \mathrm{D}$ & $\mathrm{X}$ & $X$ & $\mathrm{X}$ & & $\mathrm{O}$ & $\mathrm{O}$ & & $X$ & & & & & & \\
\hline Housing & $X$ & $\mathrm{O}$ & $\mathrm{X}$ & $\mathrm{O}$ & $X$ & $\mathrm{O}$ & & & & & $\mathrm{X}$ & & & \\
\hline
\end{tabular}

